\title{
Políticas educacionais e a qualidade da educação nos municípios fluminenses: alguns recortes
}

Adailda Gomes de Oliveira*

\section{Resumo}

Este artigo apresenta o mapeamento da situação educacional dos municípios fluminenses, a partir da análise do Plano de Ações Articuladas (PAR), implementado em 2007 pelo MEC, destacando as demandas municipais em diferentes áreas educacionais. Em veio complementar, o trabalho aborda, procedendo a uma análise multivariada, ajustando um modelo de regressão linear, como as diferenças nas médias de desempenho em Matemática para o quinto ano do Ensino Fundamental podem ser explicadas pelas políticas educacionais implementadas nos municípios. Os achados do estudo apontam que a gestão das políticas educacionais é um tema a ser considerado e perseguido de perto pela agenda política, bem como destacam a relevância de pesquisas que investiguem a associação entre tais políticas e a evolução dos indicadores educacionais.

Palavras-chave: Qualidade da Educação. Políticas Educacionais. Plano de Ações Articuladas (PAR)

\section{Introdução}

As reformas educacionais empreendidas no Brasil ao longo dos anos de 1990 trazem, com grande ímpeto, o foco na melhoria da qualidade da educação brasileira. Embora tal temática ganhe maior visibilidade a partir desse período, desde muito a literatura especializada discute os entraves aos progressos nessa área, registrando problemas como as desigualdades no acesso à escolarização e as altas taxas de reprovação e de evasão escolar. Assim, ao longo dos anos, o debate da qualidade da educação assumiu diferentes enfoques e perspectivas.

Com efeito, nos últimos anos, pesquisadores têm destacado a necessidade de adotar uma visão integrada do conceito de qualidade, tratando de modo conjunto os

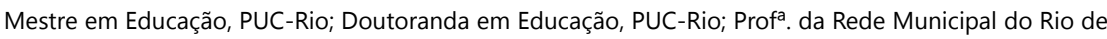
Janeiro. E-mail: adaildagm@yahoo.com.br 
indicadores de desempenho e fluxo escolar, para a maior compreensão da realidade educacional e de sua melhoria (FERNANDES; NATENZON, 2003; FERNANDES, 2004; BONAMINO; ALVES; FRANCO et al., 2007; ALVES, 2007b).

Os dados obtidos através dos sistemas estatístico-educacionais apontam para a necessidade de combinar fluxo e desempenho escolar, fazendo com que qualidade educacional signifique melhorar conjuntamente esses dois indicadores. Isso porque, sob tal perspectiva, qualidade implica em o aluno concluir a educação básica no tempo certo, progredindo na aprendizagem. Não é interessante um sistema de ensino no qual grande parcela dos alunos é reprovada ou abandona a escola antes de concluir a educação básica, ou no qual os alunos concluem a educação básica no tempo previsto, mas aprendem muito pouco. Logo, "um sistema de ensino ideal seria aquele em que todas as crianças e adolescentes tivessem acesso à escola, não desperdiçassem tempo com repetências, não abandonassem a escola precocemente e, ao final de tudo, aprendessem" (INEP, [20--?]).

Sob a égide dessa lógica, o MEC criou em 2007 o Plano do Desenvolvimento da Educação (PDE). Este plano foi lançado oficialmente pelo MEC em 24 de abril de 2007, sendo normalizado pelo Decreto Presidencial no 6.094, que dispõe sobre o "Plano de Metas Compromisso Todos pela Educação". Com o propósito declarado de melhorar a qualidade da Educação Básica, orientado por uma visão sistêmica da política educacional, ele prevê ações para todos os níveis e modalidades de ensino e para as diferentes necessidades institucionais dos entes da federação. Segundo Saviani (2007), o PDE “aparece como um grande guarda-chuva que abriga praticamente todos os programas em desenvolvimento pelo MEC. Trata-se, com efeito, de ações que cobrem todas as áreas de atuação do MEC, abrangendo os níveis e modalidades de ensino, além de medidas de apoio e de infraestrutura." (p. 1233).

No âmbito do PDE, o MEC cria igualmente o IDEB (Índice de Desenvolvimento da Educação Básica), que se propõe a medir a qualidade da educação brasileira nos âmbito nacional, estadual, municipal e em cada escola. O IDEB é um indicador de qualidade educacional que agrega os resultados de desempenho dos estudantes brasileiros (obtidos pela Prova Brasil) e rendimento escolar - taxa média de aprovação na etapa de ensino (obtidos pelo Censo Escolar). É, portanto, resultado do produto entre a média padronizada da Prova Brasil (da escola/ rede de ensino/município), ajustada para expressar valores entre 0 e 10, e o número de anos que os alunos levam para concluir uma série. 
Em sua primeira medição, no ano de 2007, foram utilizados dados do Censo Escolar de 2005 e da Prova Brasil de 2005, alcançando-se o índice médio nacional de 3,8 para os primeiros anos do Ensino Fundamental, considerado muito baixo em relação aos países da Organização para a Cooperação e Desenvolvimento Econômico (OCDE). Em vista disso, foram estabelecidas metas progressivas de melhoria desse índice, prevendo-se atingir em 2022 a média 6,0, o que representaria um desempenho educacional próximo ao que encontramos atualmente nos 20 países da OCDE mais bem colocados do mundo. Para possibilitar o acompanhamento desta meta, o MEC traçou metas de desempenho bianuais para cada município até 2022 .

No âmbito do PDE, foi criado um conjunto de políticas educacionais, direcionadas a diferentes campos de ação. Além de propor o índice, o PDE, instituiu vinte e oito diretrizes para a melhoria da educação básica, envolvendo unidades da federação, municípios e escolas, a serem alcançadas até 2022 e monitoradas pelo IDEB. Para atingi-las, é fundamental a melhora significativa do desempenho das escolas brasileiras e do fluxo escolar.

A adesão ao compromisso foi voluntária e exigiu que cada ente federativo buscasse "promover a melhoria da qualidade da educação básica em sua esfera de competência, expressa pelo cumprimento de meta de evolução do IDEB, observando-se as diretrizes relacionadas". (BRASIL, 2007). Para tanto, cada ente federado teve que elaborar um Plano de Ações Articuladas (PAR). Este pode ser definido como um conjunto de ações educacionais elaborado pelos entes federados para um período de quatro anos - 2008 a 2011 - a fim de alcançar as metas instituídas pelo MEC, quer para atingir as do IDEB local, quer para a implementação de ações determinadas pelo "Plano de Metas Compromisso Todos pela Educação", visando o aprimoramento gradativo da qualidade da educação até 2022 .

Portanto, no bojo do PDE, e tendo o IDEB como carro-chefe, o MEC institui uma nova concepção de qualidade da educação, apresentando elementos importantes para o incremento da mesma e impulsionando a formulação de inúmeras políticas públicas educacionais. Todas essas propostas contribuíram ainda mais para a diversidade da política educacional, imputando, em diferentes graus, responsabilidades às esferas governamentais pelo provimento e incremento da educação e igualmente redundando em diferentes perspectivas por partes dos entes federados quanto às prioridades das políticas educacionais. 
Nesse cenário, a atenção volta-se ainda mais para as políticas educacionais implementadas pelos Estados e municípios com vistas à melhoria da qualidade da educação, e o cumprimento das metas estabelecidas. O desafio que se coloca para pesquisadores é o de compreender como as políticas educacionais relacionamse com a evolução dos indicadores educacionais e em que medida as mesmas têm contribuído para a melhoria da educação, tanto no sentido de regularizar o fluxo quanto no de aumentar o desempenho discente nos exames padronizados nacionais, possibilitando atuações em áreas ainda a descoberto.

Com efeito, tem crescido de forma expressiva os estudos que investigam a associação entre as políticas públicas e a educação, em seus múltiplos aspectos. Este é o principal objetivo deste artigo. Face ao atual quadro político de indução de políticas educacionais pela União para os entes federativos, o presente texto tem por objetivo analisar o contexto dos municípios fluminenses com relação às políticas educacionais, bem como identificar como as mesmas relacionam-se com a evolução dos indicadores de desempenho discente. Especial enfoque é dado às políticas públicas que integram o eixo de diagnóstico do PAR. Para tanto, inicialmente, procede-se à descrição geral do PAR e das políticas analisadas. Em veio complementar, são considerados os estudos que vem sendo desenvolvidos sobre o plano. Em seguida, analisa-se como as diferenças nas médias de desempenho em matemática podem ser explicadas pelas políticas educacionais implementadas nos municípios. Por fim, algumas considerações são tecidas acerca dos resultados encontrados.

\section{Plano de Ações Articuladas (PAR) e as demandas municipais fluminenses}

O processo de elaboração do PAR encontra-se, essencialmente, dividido em duas partes. A primeira trata-se de um diagnóstico da realidade educacional de cada esfera municipal. A segunda consiste na definição de ações para a superação dos problemas educacionais identificados no diagnóstico. É, pois, a primeira parte que o presente artigo enfoca.

A partir do diagnóstico do PAR, foi realizado o mapeamento das políticas implementadas nas esferas fluminenses no período anterior à elaboração do documento (2008), sendo possível verificar as prioridades na agenda política fluminense, bem como identificar em que medida algumas de tais políticas 
encontram-se consolidadas e quais as áreas mais demandantes. Os resultados encontrados fornecem, em linhas gerais, um panorama da situação educacional nos municípios fluminenses.

O Processo de elaboração do plano, conforme explicitado, encontra-se dividido em duas etapas: a primeira consiste no diagnóstico minucioso da situação educacional local; a segunda envolve a definição de ações e subações a serem implementadas para atender as demandas assinaladas, seguida da apresentação do PAR ao prefeito. O diagnóstico é realizado por uma equipe técnica local, a qual deve ter a seguinte composição: Dirigente Municipal de Educação; técnicos da Secretaria Municipal de Educação (SME); representante dos diretores de escola; representante dos professores da zona urbana; representante dos professores da zona rural; representante dos coordenadores ou supervisores escolares; representante do quadro técnico-administrativo das escolas; representante dos conselhos escolares; representante do Conselho Municipal de Educação (quando houver).

O Instrumento diagnóstico é a principal ferramenta para a elaboração do PAR, dado que contém as questões que norteiam o exame de cada realidade municipal. Encontra-se estruturado, fundamentalmente, em duas partes: uma com questões abertas, denominada de questões pontuais, e outra com questões fechadas a serem pontuadas. Esta última está dividida em quatro grandes dimensões de análise, a saber: 1. Gestão Educacional; 2. Formação de Professores e dos Profissionais de Serviço e Apoio Escolar; 3. Práticas Pedagógicas e Avaliação; 4. Infraestrutura Física e Recursos Pedagógicos. Cada dimensão é subdividida em áreas de atuação e cada área apresenta indicadores específicos, os quais devem ser pontuados de acordo com a descrição de critérios previamente definidos, correspondentes a quatro níveis de qualidade. A decisão sobre qual das situações descritas, com a respectiva pontuação, melhor representa a situação local deve ser tomada de forma conjunta entre os integrantes da equipe técnica. Somente a partir da análise das informações educacionais disponíveis, associada à leitura e discussão compartilhada dos critérios descritos, que se deve chegar a uma pontuação ou a um valor de qualidade para cada indicador. As questões pontuais referem-se somente às dimensões de Gestão Educacional, Formação de Professores e dos Profissionais de Serviço e Apoio Escolar, e Práticas Pedagógicas e Avaliação. São perguntas específicas sobre alguns aspectos não contemplados na parte fechada do instrumento ou que necessitam de um detalhamento maior. 
Os Critérios de pontuação 3 e 4 descrevem uma situação satisfatória ou positiva, na qual o município desenvolve parcial ou integralmente as ações que favorecem o desempenho do indicador, não requerendo ações imediatas para a melhoria do mesmo. Já os critério de pontuação 1 e 2 expressam uma situação crítica ou insuficiente, na qual o município se exime de ações direcionadas à área em questão ou não desenvolve ações que favorecem o incremento do indicador. Tais pontuações exigem ações imediatas. Alguns indicadores recebem a condição não se aplica (NSA), a qual expressa uma descrição em que não há a possibilidade de registro/avaliação, em função da falta de informação ou porque a descrição não se aplica à realidade local.

Concluída essa etapa, inicia-se a elaboração do PAR propriamente dito, ou seja, o cadastro e o detalhamento de ações e subações a serem desenvolvidas para a superação das demandas educacionais locais até 2011. A definição das ações e subações é feita com base em um guia disponibilizado pelo MEC - o Guia Prático de Ações. Tais ações podem receber ou não a assistência do MEC. Com efeito, podem ser executadas por três vias: i) pelo próprio município, sob a responsabilidade da Secretaria Municipal de Educação, sem a participação do MEC; ii) pelo município com a assistência do MEC. Em tais casos, o MEC disponibiliza inúmeros recursos aos entes municipais para a implementação das ações; iii) pelo município com a assistência financeira do MEC. Nessa situação, o MEC transfere recursos financeiros aos municípios, para que a Secretaria Municipal de Educação execute as ações. Cada ação exige uma subação, com período inicial e final definidos.

Após a finalização e aprovação do PAR, é assinado um Termo de Cooperação Técnica pelo prefeito do município e pelo MEC, no qual constam as ações de assistência técnica a serem desenvolvidas por este último órgão até 2011. O próximo passo é, portanto, a execução das ações indicadas no plano.

O mapeamento das políticas fluminenses teve como eixos analíticos as dimensões e áreas de atuação das políticas educacionais apresentadas no PAR. O sistema de pontuação desenvolvido oferece um panorama da situação local com respeito a cada dimensão/área, sinalizando os campos mais demandantes. Para a operacionalização da análise, em cada dimensão, foram selecionadas algumas áreas, dentre as quais, por sua vez, foram selecionados alguns indicadores. Tendo como parâmetro as vinte e oito diretrizes preconizadas no "Plano de 
Metas Compromisso Todos pela Educação", a escolha dos indicadores baseouse na revisão da literatura sobre os fatores escolares e políticas educacionais associados à eficácia escolar, sendo selecionados os seguintes ${ }^{1}$ :

Quadro 1 - Dimensões, áreas e indicadores das políticas educacionais mapeadas nos municípios fluminenses

\section{Dimensão: Gestão Educacional}

Área de Gestão Democrática: i) indicador critérios para a escolha do diretor.

- Área de Gestão do Desenvolvimento da Educação Básica: i) indicador implantação e organização do Ensino Fundamental de nove anos.

$>$ Área de Gestão Financeira: i) indicador aplicação dos recursos de redistribuição do FUNDEB.

\section{Dimensão: Formação de Professores e de Profissionais de Serviços e Apoio Escolar}

> Área Formação Inicial de Professores da Educação Básica: i) indicador qualificação dos professores que atuam nas séries iniciais do Ensino Fundamental.

$>$ Área Formação Continuada de Professores: i) indicador existência e implementação de políticas para a formação continuada de professores.

\section{Dimensão: Práticas Pedagógicas e Avaliação}

Área elaboração e organização das práticas pedagógicas: i) indicador presença de coordenadores e supervisores pedagógicos; ii) indicador programação de reuniões pedagógicas.

Área avaliação da aprendizagem dos alunos e tempo para assistência individual/ coletiva aos alunos que apresentam dificuldade de aprendizagem: i indicador formas de registro da frequência do aluno; ii) indicador políticas de correção de fluxo.

\section{Dimensão: Infraestrutura Física e Recursos Pedagógicos}

$>$ Área instalações físicas gerais: i) indicador condições físicas das instalações gerais e mobiliário.

Área integração e expansão do uso de Tecnologias da Informação e Comunicação na Educação Pública: i) indicador existência de computadores ligados à rede mundial de computadores e utilização de recursos de informática; ii) indicador existência de recursos audiovisuais.

$>$ Recursos Pedagógicos para o desenvolvimento de práticas pedagógicas que considerem a diversidade das demandas educacionais: i) indicador suficiência e diversidade do acervo bibliográfico.

Fonte: INEP (2008a).

1 Neste respeito consultar as seguintes referências bibliográficas: ALBERNAZ; FERREIRA; FRANCO, 2002; SOARES, 2004a, 2004b; FRANCO; BONAMINO, 2005; ALVES, 2007a; FRANCO et al., 2007; GAZÓLIS, 2007; LIBÂNEO; FERREIRA; SEABRA, 2008; SAMMONS, 2008; MENEZES-FILHO; RIBEIRO, 2009. 
Procedendo-se à análise, verificou-se a condição dos municípios, em termos gerais, com respeito a cada indicador, analisando a porcentagem de municípios situados em cada critério de pontuação: em situação crítica; situação insuficiente; situação satisfatória e situação positiva (vide gráficos $1,2,3$ e 4).²

Gráfico 1 - Dimensão Gestão Educacional

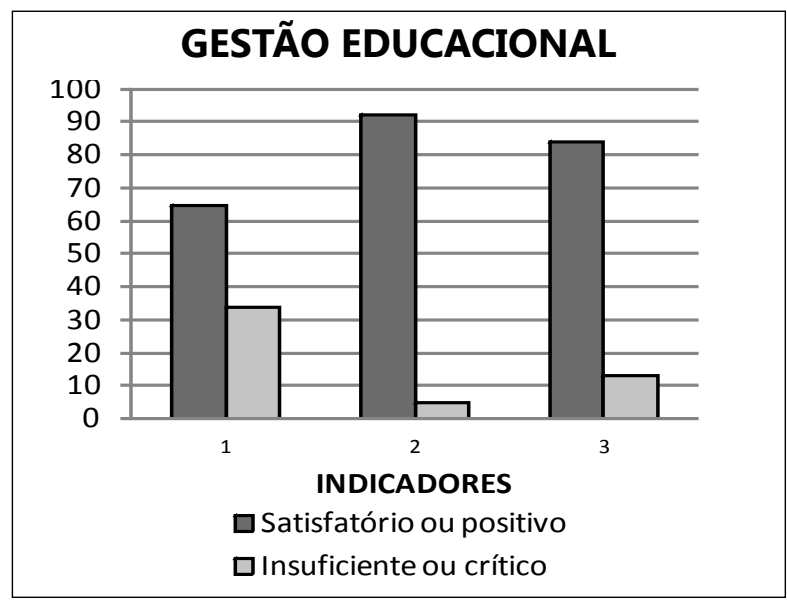

Fonte: INEP (2008b).

Gráfico 2 - Dimensão Formação de Professores

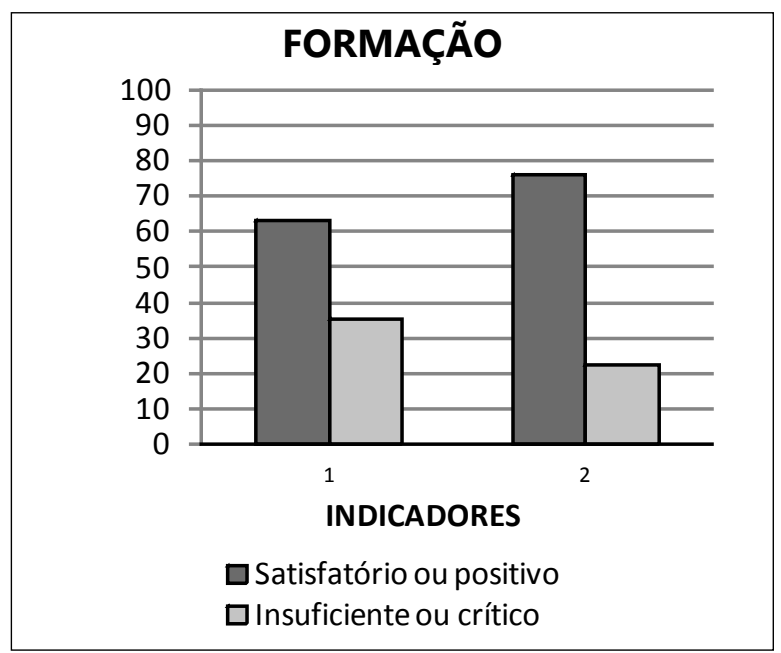

Fonte: INEP (2008b).

2 São somente considerados esses quatro critérios de qualidade, não sendo considerado o "Não se Aplica", visto que este retrata uma realidade não sujeita à avaliação. 
Gráfico 3 - Dimensão Práticas Pedagógicas e Avaliação

\section{PRÁTICAS PEDAGÓGICAS E AVALIAÇÃO}

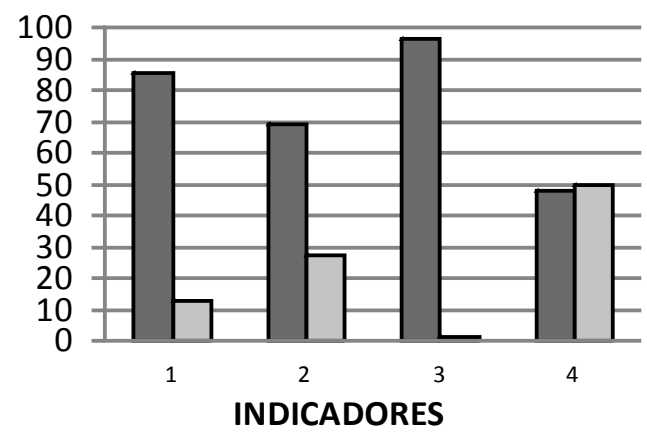

$\square$ Satisfatório ou positivo 口Insuficiente ou crítico

Fonte: INEP (2008b).

Gráfico 4 - Dimensão Infraestrutura

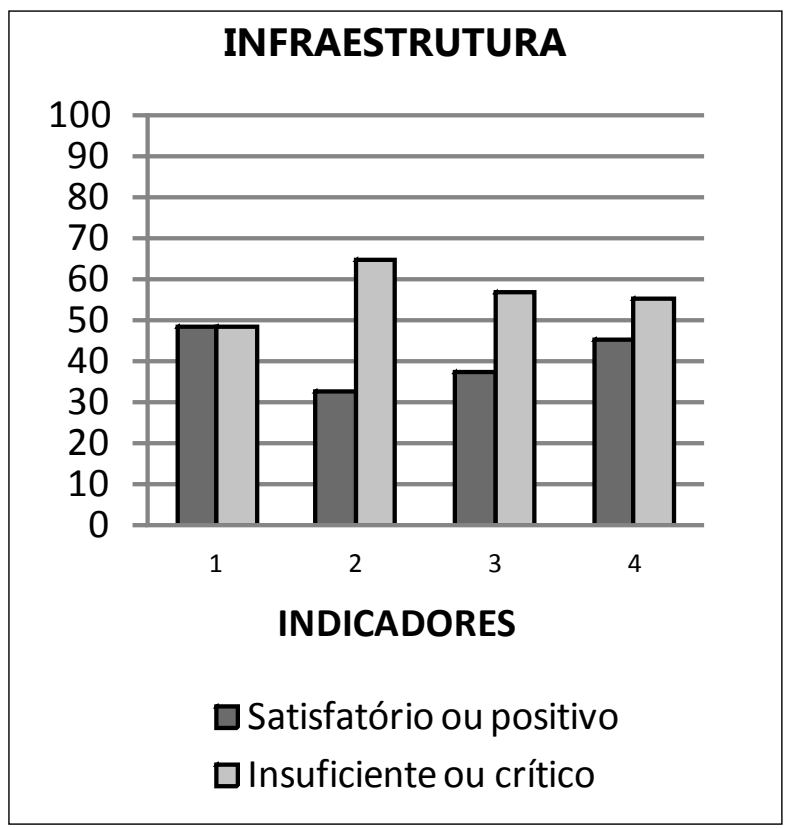

Fonte: INEP (2008b) 
Em termos gerais, fazendo um balanço da análise da dimensão Gestão Educacional, tendo em consideração o conjunto de municípios, é possível inferir que os indicadores implantação e organização do Ensino Fundamental de nove anos, e aplicação dos recursos de redistribuição e complementação do FUNDEB são os que apresentam o melhor desenvolvimento. Já o indicador referente aos critérios para a escolha da direção escolar demanda ações mais efetivas, dado que os percentuais de municípios nas melhores categorias são relativamente baixos.

No que se refere à implementação de políticas de formação inicial e continuada, a análise permite concluir que as práticas de formação continuada já estão mais bem consolidadas que as de formação inicial. Duas interpretações podem ser feitas a partir desses resultados. A primeira é que a Resolução 01/2002, que permitiu o exercício na Educação Infantil e nas séries iniciais do Ensino Fundamental aos professores com formação Normal de Ensino Médio, "freou" o processo de expansão da formação inicial em nível superior ensejado pela LDB de 96. Sem essa "brecha" no texto legal, provavelmente o quantitativo de professores da Educação Infantil e dos anos iniciais do Ensino Fundamental com formação superior em curso de licenciatura seria expressivamente maior. A segunda leitura é a de que a expansão das políticas de formação continuada pode estar associada ao fato de que, nos últimos anos, no âmbito da gestão escolar e dos estudos sobre as escolas eficazes, a formação do professor em serviço tem sido identificada e valorizada como um fator imprescindível para a melhoria da qualidade do ensino, redundando na sistematização e implementação de inúmeros programas e cursos de capacitação docente.

O mapeamento da dimensão "Práticas pedagógicas e Avaliação" mostrou que as políticas relacionadas à frequência do aluno e à execução de reuniões pedagógicas têm prioridade na agenda política; enquanto que as questões de correção do fluxo escolar e a presença de coordenadores ou supervisores pedagógicos nas escolas necessitam ser consolidadas, sendo ainda mais demandantes as de correção da distorção idade-série.

Analisando o processo de implementação das políticas direcionadas à Infraestrutura e Recursos Pedagógicos, é possível inferir que, de modo geral, esse é um campo de atuação acentuadamente demandante nos municípios fluminenses. Com efeito, é a dimensão que apresenta os piores resultados para todos os indicadores, o que sinaliza que o grau de expansão das políticas aí desenvolvidas é muito incipiente, necessitando de ações mais contundentes. Dentre os indicadores examinados, o que se refere à existência de computadores ligados à rede mundial de computadores e 
utilização de recursos de informática para atualização de conteúdos e realização de pesquisas é o que apresenta o desempenho mais desfavorável, seguido do indicador existência de recursos audiovisuais. Esse resultado pode estar associado ao fato de que uma parcela expressiva dos municípios não realiza um planejamento adequado dos recursos financeiros, e tampouco avalia as áreas prioritárias.

Os resultados aqui reportados coadunam-se com outros achados de pesquisa sobre o PAR, em seus múltiplos aspectos, de municípios de diferentes Estados brasileiros, bem como complementa tais achados, agregando conhecimentos aos estudos sobre políticas educacionais. A seguir, destacam-se alguns de tais estudos, cujo foco é o PAR.

Farenzena, Mosna e Schuch (2011) investigaram o processo de implementação das ações e subações propostas no PAR de três municípios priorizados ${ }^{3}$ do Rio Grande do Sul, os quais já haviam concluído seus planos no final de 2007, analisando em que medida tais ações e subações s foram executadas e quais os fatores que dificultaram a execução das mesmas. Os resultados apontaram tanto para aspectos negativos quanto positivos na implementação da política. Dentre os negativos, destaca-se o fato de muitas das ações não terem sido iniciadas, por inúmeros fatores. Quanto aos positivos, ressalta-se a apropriação das propostas do PAR pelos dirigentes municipais e a sua paulatina execução. Outro achado do estudo que merece ser destacado é o fato das dimensões gestão e infraestrutura apresentarem o maior número de indicadores nas categorias insuficiente e crítica.

Batista (2011) examinou o PAR de vinte e quatro municípios considerados prioritários no Rio Grande do Sul, com ênfase na dimensão da Gestão Educacional, dando especial enfoque aos indicadores da área da "Gestão Democrática: articulação e desenvolvimento dos sistemas de ensino". A autora verificou que o indicador Plano Municipal de Educação tem um maior percentual de municípios nas piores categorias $(87,50 \%)$, o que sugere que grande parte dos municípios prioritários não realizou o planejamento educacional municipal; e que o indicador critério para escolha da direção da escola aponta maior percentual nos melhores patamares $(62,50 \%)$, indicando que há critérios definidos para o provimento do cargo, ainda que não sejam os mais adequados. Além disso, o estudo registra ainda que, de modo geral, a elaboração do PAR em tais municípios aponta que a maior parte dos sistemas e redes de ensino público municipais do RS ignora os processos e práticas de gestão democrática da educação.

3 Municípios priorizados são aqueles cujo o IDEB se encontra abaixo da média nacional. 
As dimensões consideradas prioritárias por gestores municipais paulistas foram consideradas por Bello (2011). A pesquisadora investigou o PAR de 34 municípios prioritários de São Paulo, traçando um panorama das necessidades educacionais identificadas por cada gestor municipal. Os dados reportados demonstram que as dimensões gestão educacional e infraestrutura física e recursos pedagógicos foram priorizadas pelos municípios.

O trabalho de Mafassioli e Marchand (2011) analisou, igualmente em municípios do Rio Grande do Sul, as competências dos entes federados na implementação do PAR e o regime de colaboração que se estabeleceu entre eles, identificando e dimensionando a participação técnica e financeira de cada um deles na execução das ações e subações indicadas no plano. Os resultados sinalizam que a implementação do PAR tem promovido uma maior articulação e colaboração entre a União e os municípios, em termos de assistência. No entanto, segundo as autoras, os desafios na ampliação dos recursos financeiros permanecem, uma vez que a participação da União se dá, majoritariamente, em termos técnicos. A despeito disso, o estudo ressalta que o PAR possibilitou uma redistribuição mais justa dos recursos da União, superando o injusto "balcão de negócios" que ocorria em gestões anteriores, por favorecer a transferência de recursos baseada em critérios públicos, objetivos e transparentes.

O PAR enquanto instrumento de planejamento da educação foi discutido por Sousa (2011). O autor problematiza os limites e as possibilidades do planejamento educacional no âmbito do PAR, registrando que o mesmo não pode ser considerado um instrumento de planejamento da educação no município, uma vez que não favorece efetivamente a participação popular nos processos de planejamento e gestão, bem como tem o caráter centralizador, normativo e tecnocrático. Segundo os dados trazidos pelo o autor, o PAR homogeneíza a imensa e diversificada realidade educacional brasileira. Apesar dos limites do PAR salientados no estudo, aspectos positivos da política também são destacados, qual seja: o plano permite o estabelecimento de regras claras para o atendimento do MEC aos entes federativos.

Com efeito, a literatura educacional demonstra que os estudos voltados para a análise de políticas públicas têm relevância acadêmica e contribuem para produção de conhecimentos - tanto teóricos, quanto práticos - da política educacional e da qualidade da educação. 
Tendo sido feito o mapeamento da situação educacional das esferas municipais fluminenses, sendo apontadas as prioridades das políticas educacionais e as áreas mais demandantes para a melhoria da qualidade da educação, passou-se a investigar a relação entre algumas destas políticas e o desempenho discente, o que será examinado na próxima seção.

\section{Políticas públicas educacionais e desempenho discente}

O mapeamento da situação educacional dos municípios fluminenses aponta para uma realidade de múltiplas facetas e contextos no que se refere à implementação das políticas públicas nas esferas municipais. Conforme exposto na seção anterior, algumas políticas encontram-se bem consolidadas, enquanto outras mostram-se em grau ainda muito incipiente de expansão. Dada a relevância de tais políticas para a melhoria da qualidade da educação, importa, pois, considerar os efeitos das mesmas sobre o desempenho dos alunos. Este é o objetivo da análise que se segue. Assim, a presente seção analisa a relação entre as políticas públicas implementadas nas instâncias municipais do Estado do Rio de Janeiro e o desempenho médio em Matemática da Rede Municipal de ensino no $5^{\circ}$ ano do Ensino Fundamental. Para tanto, procedeu-se a uma análise multivariada, ajustando um modelo de regressão linear, o qual será explicitado a seguir.

Conforme especificado, o próximo passo da investigação envolveu a estimação dos efeitos relacionados às políticas educacionais, a partir de variáveis construídas da análise do PAR, discutidas na seção anterior. Estimou-se o modelo para os municípios que possuíam o PAR elaborado no período da presente análise. Como dos 92 municípios fluminenses, somente 62 possuíam PAR, esta etapa do estudo refere-se somente a este subgrupo. A equação de regressão tomada como base para a estimação das políticas públicas educacionais seguiu a seguinte forma:

Média_ProfMat_2007 $=\alpha+\beta$ 1(média_ProfMat_2005) $+\beta 2$ (log_gasto) + $\beta 3($ recur_fundeb) $)+\beta 4($ form_cont $)+\beta 5$ (infra) $+\beta 6$ (ens_9 anos) $+\beta 7$ (esc_dire) $+\beta 8$ (ava_pme) $+\beta 9$ (carre_mag) $+\beta 10$ (subst_prof) $+\beta 11($ form_ini $)+\beta$ $12($ coord_ped $)+\beta 13$ (reun_ped) $+\beta 14$ (freq_alun $)+\beta 15$ (pol_flu) $+\beta 16$ $($ comput_rede $)+\beta 17$ (rec_aud) $+\beta 18$ (Acer_bibl) $+\epsilon$ 
Os dados atinentes ao desempenho médio das redes municipais são provenientes da Prova Brasil nos anos de 2005 e 2007, para a $4^{\mathrm{a}}$ série (quinto ano) em Matemática. São considerados os resultados em Matemática pelo fato de que, como amplamente mostrado pelos estudos sobre o efeito escola, os ganhos nesta área são mais determinados pela escola do que na área de Língua Portuguesa, que é consideravelmente influenciada por fatores não escolares e desenvolve-se em diferentes ambientes sociais frequentados pelos alunos (FRANCO; BONAMINO, 2002; FRANCO et al., 2007; FONTANIVE, 2009). A variável dependente utilizada é a média de desempenho discente em Matemática em 2007 e a variável de controle é o logaritmo do gasto dos municípios no Ensino Fundamental por aluno. Isso significa que os efeitos encontrados para as políticas avaliadas já levam em consideração as diferenças relacionadas ao gasto por aluno das diferentes redes de ensino.

Já os indicadores educacionais têm como fonte o sistema de consulta EDUDATABRASIL - Sistema de Estatísticas Educacionais -, vinculado ao INEP, bem como o conjunto de Indicadores Demográficos e Educacionais fornecidos pelo MEC para cada município.

Dentre as variáveis de políticas públicas educacionais construídas da análise do PAR, somente algumas apresentaram impacto significativo, a saber: a implantação e organização do Ensino Fundamental de nove anos; aplicação dos recursos de redistribuição e complementação do FUNDEB; existência e implementação de políticas para a formação continuada de professores; e condições físicas das instalações gerais e o mobiliário. Os resultados obtidos para tais políticas serão discutidos à frente.

A identificação das variáveis, a estatística descritiva e os resultados para o modelo são apresentados a seguir.

Quadro 2 - Variáveis utilizadas no modelo

\begin{tabular}{|l|l|l|}
\hline Variável & Tipo de variável & Descrição \\
\hline DEPENDENTE & Contínua & $\begin{array}{l}\text { Proficiência média das redes mu- } \\
\text { nicipais em 2007 na Prova Brasil. }\end{array}$ \\
\hline $\begin{array}{l}\text { Desempenho Médio da rede de } \\
\text { ensino em } 2007\end{array}$ & \multicolumn{2}{|l|}{} \\
\hline CONTROLE & Contínua & $\begin{array}{l}\text { Log do gasto da rede municipal } \\
\text { por aluno matriculado na mesma. }\end{array}$ \\
\hline Logaritmo do gasto por aluno
\end{tabular}

(continua) 


\begin{tabular}{|c|c|c|}
\hline Variável & Tipo de variável & Descrição \\
\hline \multicolumn{3}{|l|}{ EXPLICATIVAS } \\
\hline $\begin{array}{l}\text { Indicador Implantação e Organi- } \\
\text { zação do E.F. de nove anos }\end{array}$ & Dicotômica & $\begin{array}{l}\text { Indica se a rede de ensino tem o } \\
\text { E. F. com duração de nove anos e } \\
\text { se foram feitas as devidas reestru- } \\
\text { turações pedagógicas ( } 1=\text { situação } \\
\text { positiva ou satisfatória/ } 0=\text { situa- } \\
\text { ção crítica ou insatisfatória). }\end{array}$ \\
\hline $\begin{array}{l}\text { Indicador aplicação dos recursos } \\
\text { e complementação do FUNDEB }\end{array}$ & Dicotômica & $\begin{array}{l}\text { Indica se a aplicação dos recursos } \\
\text { de redistribuição e complemen- } \\
\text { tação do FUNDEB acontece de } \\
\text { acordo com os princípios legais e } \\
\text { se é feito um diagnóstico das áre- } \\
\text { as prioritárias ( } 1=\text { situação positiva } \\
\text { ou satisfatória/ } 0=\text { situação crítica } \\
\text { ou insatisfatória). }\end{array}$ \\
\hline $\begin{array}{l}\text { Indicador políticas para a forma- } \\
\text { ção continuada de professores }\end{array}$ & Dicotômica & $\begin{array}{l}\text { Indica se existem políticas volta- } \\
\text { das para a formação continuada } \\
\text { de professores na rede de ensino } \\
\text { ( } 1=\text { situação positiva ou satis- } \\
\text { fatória/ } 0=\text { situação crítica ou } \\
\text { insatisfatória). }\end{array}$ \\
\hline $\begin{array}{l}\text { Indicador condições físicas das } \\
\text { instalações e mobiliário }\end{array}$ & Dicotômica & $\begin{array}{l}\text { Indica se as instalações para o en- } \\
\text { sino da rede atendem, em grande } \\
\text { medida, os requisitos necessários } \\
\text { e se o material está, em grande } \\
\text { parte, conservado ( } 1=\text { situação po- } \\
\text { sitiva ou satisfatória/ } 0=\text { situação } \\
\text { crítica ou insatisfatória). }\end{array}$ \\
\hline $\begin{array}{l}\text { Indicador critérios para a esco- } \\
\text { Iha da Direção Escolar }\end{array}$ & Dicotômica & $\begin{array}{l}\text { Indica se existem critérios defini- } \\
\text { dos para a escolha de diretores, } \\
\text { os quais são de conhecimento } \\
\text { de todos ( } 1=\text { situação positiva ou } \\
\text { satisfatória/ } 0=\text { situação crítica ou } \\
\text { insatisfatória). }\end{array}$ \\
\hline $\begin{array}{l}\text { Indicador existência, acompa- } \\
\text { nhamento e avaliação do PME }\end{array}$ & Dicotômica & $\begin{array}{l}\text { Indica se o município apresen- } \\
\text { ta um PME e um programa de } \\
\text { acompanhamento e avaliação das } \\
\text { metas do mesmo ( } 1=\text { situação po- } \\
\text { sitiva ou satisfatória/ } 0=\text { situação } \\
\text { crítica ou insatisfatória). }\end{array}$ \\
\hline
\end{tabular}




\begin{tabular}{|c|c|c|}
\hline Variável & Tipo de variável & Descrição \\
\hline $\begin{array}{l}\text { Indicador plano de carreira para } \\
\text { o magistério }\end{array}$ & Dicotômica & $\begin{array}{l}\text { Indica se existe plano de carreira } \\
\text { para o magistério com boa imple- } \\
\text { mentação ( } 1=\text { situação positiva ou } \\
\text { satisfatória/ } 0=\text { situação crítica ou } \\
\text { insatisfatória). }\end{array}$ \\
\hline $\begin{array}{l}\text { Indicador cálculo de remoção ou } \\
\text { substituição de professores }\end{array}$ & Dicotômica & $\begin{array}{l}\text { Indica se a SME e as escolas } \\
\text { calculam o número de remoções } \\
\text { e substituições do quadro de } \\
\text { professores da rede; e realizam } \\
\text { um planejamento para que no ano } \\
\text { seguinte as remoções e substitui- } \\
\text { ções sejam reduzidas ( } 1=\text { situação } \\
\text { positiva ou satisfatória/ } 0=\text { situa- } \\
\text { ção crítica ou insatisfatória). }\end{array}$ \\
\hline $\begin{array}{l}\text { Indicador formação inicial de } \\
\text { professores dos anos iniciais } \\
\text { do E. F. }\end{array}$ & Dicotômica & $\begin{array}{l}\text { Indica se mais de } 50 \% \text { ou todos } \\
\text { os professores da rede que atuam } \\
\text { nas séries/anos iniciais do E.F. } \\
\text { possuem formação superior em } \\
\text { curso de licenciatura ( } 1=\text { situação } \\
\text { positiva ou satisfatória/ } 0=\text { situa- } \\
\text { ção crítica ou insatisfatória). }\end{array}$ \\
\hline $\begin{array}{l}\text { Indicador presença de coor- } \\
\text { denadores ou supervisores } \\
\text { pedagógicos }\end{array}$ & Dicotômica & $\begin{array}{l}\text { Indica se mais de } 50 \% \text { ou todas } \\
\text { as escolas da rede possuem } \\
\text { coordenadores ou supervisores } \\
\text { pedagógicos em tempo integral } \\
\text { ( } 1=\text { situação positiva ou satis- } \\
\text { fatória/ } 0=\text { situação crítica ou } \\
\text { insatisfatória). }\end{array}$ \\
\hline $\begin{array}{l}\text { Indicador programação de reu- } \\
\text { niões pedagógicas }\end{array}$ & Dicotômica & $\begin{array}{l}\text { Indica se existem reuniões peda- } \\
\text { gógicas e horários de trabalhos } \\
\text { pedagógicos, periodicamente, en- } \\
\text { volvendo a participação de toda a } \\
\text { comunidade escolar ( } 1=\text { situação } \\
\text { positiva ou satisfatória/ } 0=\text { situa- } \\
\text { ção crítica ou insatisfatória). }\end{array}$ \\
\hline $\begin{array}{l}\text { Indicador formas de registro da } \\
\text { frequência do aluno }\end{array}$ & Dicotômica & $\begin{array}{l}\text { Indica se o município apresenta } \\
\text { mecanismos claros e definidos } \\
\text { para o registro diário da frequên- } \\
\text { cia dos alunos. ( } 1=\text { situação positi- } \\
\text { va ou satisfatória/ } 0=\text { situação } \\
\text { crítica ou insatisfatória). }\end{array}$ \\
\hline
\end{tabular}




\begin{tabular}{|c|c|c|}
\hline Variável & Tipo de variável & Descrição \\
\hline $\begin{array}{l}\text { Indicador políticas de correção } \\
\text { de fluxo }\end{array}$ & Dicotômica & $\begin{array}{l}\text { Quando existem políticas especí- } \\
\text { ficas implementadas para a corre- } \\
\text { ção de fluxo (repetência e evasão), } \\
\text { que oferecem condições para } \\
\text { superar as dificuldades de apren- } \\
\text { dizagem e prevenir as distorções } \\
\text { idade-série ( } 1=\text { situação positiva } \\
\text { ou satisfatória/ } 0=\text { situação crítica } \\
\text { ou insatisfatória). }\end{array}$ \\
\hline $\begin{array}{l}\text { Indicador computadores ligados } \\
\text { à rede mundial }\end{array}$ & Dicotômica & $\begin{array}{l}\text { Indica se parte ou todas as escolas } \\
\text { da rede possuem computado- } \\
\text { res ligados à rede mundial de } \\
\text { computadores e se a quantidade } \\
\text { existente permite a utilização por } \\
\text { parte de professores e alunos para } \\
\text { acesso aos conteúdos e realização } \\
\text { de pesquisas ( } 1=\text { situação positiva } \\
\text { ou satisfatória/ } 0=\text { situação crítica } \\
\text { ou insatisfatória). }\end{array}$ \\
\hline $\begin{array}{l}\text { Indicador existência de recursos } \\
\text { audiovisuais }\end{array}$ & Dicotômica & $\begin{array}{l}\text { Indica se parte ou todas as escolas } \\
\text { da rede possuem sala específica } \\
\text { de vídeo equipada com TV, Vídeo/ } \\
\text { DVD e equipamento multimídia, e } \\
\text { têm disponíveis materiais pedagó- } \\
\text { gicos atualizados para a utilização } \\
\text { destes recursos ( } 1=\text { situação po- } \\
\text { sitiva ou satisfatória/ } 0=\text { situação } \\
\text { crítica ou insatisfatória). }\end{array}$ \\
\hline $\begin{array}{l}\text { Indicador suficiência e diversida- } \\
\text { de do acervo bibliográfico }\end{array}$ & Dicotômica & $\begin{array}{l}\text { Indica se o acervo é adequado às } \\
\text { etapas de ensino ofertadas pelas } \\
\text { escolas e se atende às necessida- } \\
\text { des dos alunos e professores ( } 1= \\
\text { situação positiva ou satisfatória/ } 0= \\
\text { situação crítica ou insatisfatória). }\end{array}$ \\
\hline
\end{tabular}

Fonte: a autora (2014).

Tabela 1 - Estatística descritiva das variáveis utilizadas no modelo

\begin{tabular}{lllll}
\hline Variáveis & Média & Dp & Min & Max \\
\hline Log_gasto & 3,31 & 0,21 & 2,48 & 3,74 \\
\hline Implantação e organização do E.F de 9 anos & 0,92 & - & - & - \\
\hline Aplicação dos recursos e complementação do FUNDEB & 0,84 & - & - & - \\
\hline
\end{tabular}




\begin{tabular}{|c|c|c|c|c|}
\hline Variáveis & Média & $\mathrm{Dp}$ & Min & Max \\
\hline $\begin{array}{l}\text { Indicador políticas para a formação continuada de } \\
\text { professores }\end{array}$ & 0,76 & - & - & - \\
\hline Condições físicas das instalações e mobiliário & 0,49 & - & - & - \\
\hline Indicador critérios para a escolha da Direção Escolar & 0,64 & - & - & - \\
\hline Indicador existência, acompanhamento e avaliação do PME & 0,18 & - & - & - \\
\hline Indicador plano de carreira para o magistério & 0,74 & - & - & - \\
\hline $\begin{array}{l}\text { Indicador cálculo de remoção ou substituição de profes- } \\
\text { sores }\end{array}$ & 0,81 & - & - & - \\
\hline $\begin{array}{l}\text { Indicador formação inicial de professores dos anos } \\
\text { iniciais do E. F. }\end{array}$ & 0,63 & - & - & - \\
\hline $\begin{array}{l}\text { Indicador presença de coordenadores ou supervisores } \\
\text { pedagógicos }\end{array}$ & 0,70 & - & - & - \\
\hline Indicador programação de reuniões pedagógicas & 0,85 & - & - & - \\
\hline Indicador formas de registro da frequência do aluno & 0,97 & - & - & - \\
\hline Indicador políticas de correção de fluxo & 0,49 & - & - & - \\
\hline Indicador computadores ligados à rede mundial & 0,32 & - & - & - \\
\hline Indicador existência de recursos audiovisuais & 0,37 & - & - & - \\
\hline Indicador suficiência e diversidade do acervo bibliográfico & 0,45 & - & - & - \\
\hline
\end{tabular}

Fonte: a autora (2014).

Tabela 2 - Coeficientes do modelo estimado 2

\begin{tabular}{|c|c|c|}
\hline & Coef. & $\mathrm{p}$-value \\
\hline Log_gasto & 21,57 & 0,069 \\
\hline Implantação e organização do E.F de 9 anos & $-11,24$ & 0,010 \\
\hline Aplicação dos recursos e complementação do FUNDEB & 10,95 & 0,049 \\
\hline Formação continuada & 7,74 & 0,095 \\
\hline Condições físicas das instalações e mobiliário & 8,57 & 0,033 \\
\hline Indicador critérios para a escolha da Direção Escolar & 0,03 & 0,995 \\
\hline $\begin{array}{l}\text { Indicador existência, acompanhamento e avaliação } \\
\text { do PME }\end{array}$ & 1,27 & 0,806 \\
\hline Indicador plano de carreira para o magistério & $-4,26$ & 0,340 \\
\hline $\begin{array}{l}\text { Indicador cálculo de remoção ou substituição de } \\
\text { professores }\end{array}$ & $-0,542$ & 0,909 \\
\hline
\end{tabular}




\begin{tabular}{lll}
\hline & Coef. & p-value \\
\hline $\begin{array}{l}\text { Indicador formação inicial de professores dos anos } \\
\text { iniciais do E. F. }\end{array}$ & $-1,68$ & 0,718 \\
$\begin{array}{l}\text { Indicador presença de coordenadores ou superviso- } \\
\text { res pedagógicos }\end{array}$ & $-5,35$ & 0,271 \\
$\begin{array}{l}\text { Indicador programação de reuniões pedagógicas } \\
\text { Indicador formas de registro da frequência do aluno }\end{array}$ & $-4,81$ & 0,651 \\
$\begin{array}{l}\text { Indicador políticas de correção de fluxo } \\
\text { Indicador computadores ligados à rede mundial }\end{array}$ & $-0,11$ & 0,642 \\
$\begin{array}{l}\text { Indicador existência de recursos audiovisuais } \\
\text { Indicador suficiência e diversidade do acervo biblio- } \\
\text { gráfico }\end{array}$ & $-3,94$ & 0,99 \\
\hline R2 & 0,400 & 0,916 \\
\hline
\end{tabular}

Fonte: a autora (2014).

Tendo sido estabelecido o modelo de estimação, importa considerar as relações encontradas entre as variáveis analisadas, em especial, as políticas educacionais e o desempenho médio das redes municipais. Dentre as diversas variáveis incluídas no modelo, destaca-se que muitas delas não tiveram efeitos significativos como, por exemplo, as relacionadas aos critérios para a escolha da Direção Escolar; à existência, acompanhamento e avaliação do PME; às políticas de correção de fluxo; à formação inicial de professores, dentre outras. As seções a seguir serão dedicadas à discussão dos resultados das variáveis que tiveram resultados significativos.

\title{
4 Implantação e organização do ensino fundamental de nove anos
}

\begin{abstract}
A variável indicadora da implantação e organização do Ensino Fundamental de nove anos apresenta impacto negativo e marginalmente significativo no desempenho médio das redes municipais. Para os municípios que possuem tal política consolidada, o desempenho médio é, em média, 11,24 pontos abaixo dos municípios que ainda não possuem a política amplamente desenvolvida. Este resultado corrobora os achados do estudo de Alves (2007a), o qual igualmente reportou efeito negativo e não significativo da variável sobre o desempenho
\end{abstract}


médio das redes de ensino das capitais brasileiras. Uma explicação possível para esse fato é a de que tal política tem sido implementada em contextos nos quais as escolas não se encontram preparadas para materializar as propostas requeridas pela nova estrutura. Com efeito, uma parcela significativa dos municípios, embora tenha implantado o Ensino Fundamental de nove anos, ainda não reestruturou totalmente a proposta pedagógica das escolas, os espaços físicos e os materiais pedagógicos.

Caminhando nessa direção, a pesquisa desenvolvida por Gorni (2007), junto a doze escolas públicas no Paraná, sobre como a proposta de implantação do Ensino Fundamental de nove anos chegou às instituições escolares e de como as mesmas se prepararam para este processo apontou que, na maior parte das escolas, não havia condições para a implantação da proposta. Não se observou uma ação planejada, organizada e sistemática de assessoria às escolas na implantação do Ensino Fundamental ampliado, verificando-se, ao contrário, diferentes níveis de conhecimentos e dúvidas entre professores e diretores.

Esse quadro chama a atenção para o fato de que, no empenho de conformarse ao dispositivo legal, inúmeros municípios aderiram à ampliação do Ensino Fundamental sem o planejamento, preparo e ajustes necessários. Nesse sentido, Gorni (2007) ainda sinaliza que o que determinará se a política redundará ou não em melhoria da qualidade do ensino é a maneira como a proposta chega às escolas, é apreendida, analisada e, por sua vez, implementada. Dessa forma, os dados aqui apresentados apontam que há muito para fazer no processo de materialização da expansão do Ensino Fundamental obrigatório, para que a proposta efetivamente resulte na promoção da aprendizagem discente.

\section{Aplicação dos recursos e complementação do Fundo de Manutenção e Desenvolvimento da Educação Básica e de Valorização dos Profissionais da Educação (FUNDEB)}

A variável indicadora dos recursos e complementação do FUNDEB reportou impacto positivo na proficiência discente. Os municípios que aplicam os recursos de redistribuição e complementação do FUNDEB de acordo com os princípios legais e determinam as áreas prioritárias, mesmo que eventualmente, a partir de um diagnóstico situacional, e realizam o controle social, ainda que 
parcialmente, pelo Conselho responsável, obtém, em média, o aumento de 10,95 pontos no desempenho das redes municipais. Este resultado aparentemente parece divergir do encontrado pela literatura educacional, tanto no âmbito nacional quanto internacional, a qual tem registrado que não existe relação direta entre gastos educacionais e desempenho escolar. O aumento de recursos empregados na educação não garante, necessariamente, melhorias na qualidade do ensino. No entanto, tais resultados estão estreitamente relacionados, o que ficará claro à frente. Inúmeros estudos têm investigado tal associação. Dentre estes, destaca-se o estudo realizado por Menezes-Filho e Amaral (2009), o qual serviu de base para a análise aqui desenvolvida. Os autores investigaram a relação entre as despesas por aluno no Ensino Fundamental nas Redes Municipais brasileiras em 2005 e o desempenho dos alunos da $4^{a}$ (quinto ano) e $8^{\mathrm{a}}$ (nono ano) séries em Matemática e Língua Portuguesa, a partir dos testes da Prova Brasil, igualmente de 2005, e concluíram que o efeito dos gastos sobre o desempenho é muito pequeno e estatisticamente insignificante. Uma possível interpretação para tal resultado dada pelos autores, a qual igualmente é a interpretação adotada para os dados aqui encontrados, é a de que há fatores relacionados à gestão desses recursos no sistema educacional que impedem que os mesmos sejam convertidos em melhor qualidade da educação. Tal suposição nos remete aos achados das pesquisas sobre eficácia escolar que mostram que os recursos, inclusive os financeiros, quando existentes e bem usados importam (ALBERNAZ; FERREIRA; FRANCO, 2002; SOARES 2004a; FRANCO et al. 2007). Fato este que leva à conclusão de que o fator diferencial, portanto, que determinará se os gastos ou os recursos redundarão em aumento cognitivo, é a gestão coerente e eficiente dos mesmos. Os gastos têm efeito quando efetivamente usados de modo coerente no sistema de ensino. Essa é a idéia subjacente à aplicação dos recursos do FUNDEB. Os municípios que o utilizam com base em um planejamento adequado, tendo em conta as áreas prioritárias, estão contribuindo para que os recursos financeiros sejam traduzidos em melhoria da qualidade da educação.

Tal dado acaba por reforçar a literatura que afirma que os recursos escolares, incluindo o financeiro, importam e que a gestão adequada dos mesmos é fator determinante para a promoção da aprendizagem. Igualmente indicam que não basta o aumento nos recursos destinados à educação, dado que não há uma relação direta entre os recursos utilizados pelo sistema de ensino e a qualidade do mesmo. É preciso, antes, saber utilizá-los de forma coerente. 


\section{Implementação de políticas para a formação continuada de professores}

A questão da formação continuada de professores tem ganhado vulto no cenário político educacional, sendo apontada como um fator importante para a eficácia escolar. Tal fato está relacionado, fundamentalmente, a dois fatores. O primeiro diz respeito à exigência da melhoria da qualidade da educação. Em um contexto de baixo desempenho discente e de altas taxas de reprovação e evasão, a figura do professor assume um papel central, sendo requerida a criação de espaços de formação docente em serviço e a reconstrução das práticas pedagógicas. O segundo está relacionado às novas demandas do mundo do trabalho. Em uma sociedade de constantes transformações, com a sempre crescente formulação e incorporação de novas tecnologias, o aprimoramento profissional se faz premente. Além disso, há que se considerar que a criação e regulamentação do Fundo de Manutenção e Valorização do Magistério (FUNDEF) e, posteriormente, a do Fundo de Manutenção e Desenvolvimento da Educação Básica e de Valorização dos Profissionais da Educação (FUNDEB), impulsionou ainda mais a oferta de programas de formação continuada, pois tal formação passa a contar com uma política de financiamento até então inexistente.

No entanto, cabe enfatizar que, a despeito de tal expansão, Fontanive (2009) sinaliza que a maior parte dos programas de formação continuada é de caráter compensatório, voltada para corrigir uma má formação inicial do professor, e não atende a sua devida função de atualização e aprofundamento dos conteúdos e práticas de ensino. Além disso, a autora também ressalta que no Brasil ainda não se desenvolveu um sistema apropriado e eficiente de avaliação dos cursos e dos professores que os frequentam, para a identificação de novas práticas que resultam em melhoria da aprendizagem dos alunos. Face a esse cenário, importa, pois, investigar em que medida as políticas de formação continuada têm favorecido o aumento do desempenho discente. Nesse sentido, o presente trabalho pretende contribuir. No modelo aqui estimado, a variável implementação de políticas para a formação continuada de professores está associada a um aumento médio de 7,74 pontos no desempenho médio das redes municipais.

Todavia, também são incipientes no Brasil as pesquisas que investigam a relação dos programas/ políticas de formação continuada com o desempenho discente. Dentre os existentes, destaca-se o estudo acima mencionado, realizado por Fontanive (2009). Tal estudo analisou os efeitos de um Programa de Capacitação 
no Tocantins, realizado durantes seis anos, sobre o desempenho discente, reportando impactos positivos do mesmo, uma vez que o programa favoreceu o desenvolvimento de práticas de ensino associadas à eficácia escolar.

Assim, é possível inferir que os resultados aqui obtidos estão alinhados com a literatura nacional que destaca a associação positiva entre formação continuada e desempenho educacional; fato este que sugere a necessidade de uma maior implementação de mecanismos de monitoramento dos programas de capacitação do professor e de pesquisas sobre os efeitos dos mesmos.

\section{Condições físicas das instalações e mobiliários}

O coeficiente da variável relacionada às condições físicas das instalações e mobiliários apresenta associação positiva sobre o desempenho médio das redes de ensino municipais que contam, em grande medida, com instalações apropriadas para um ambiente de aprendizagem, que atendem as dimensões para o número de alunos, acústica, iluminação, ventilação, limpeza, e que apresentam mobiliário conservado. Logo, as redes com melhores instalações físicas gerais e mobiliários têm um aumento médio de 8,57 pontos no desempenho. Tal resultado está alinhado às pesquisas nacionais sobre escolas eficazes, as quais reportam efeito positivo das condições de infraestrutura no desempenho discente. No Brasil, a presença, a conservação e o uso dos recursos escolares importam, dada a grande variabilidade dos mesmos entre as escolas.

Diversos estudos reportam resultados semelhantes. Riani (2004) analisou o efeito dos recursos sobre a probabilidade dos indivíduos de 7 a 14 anos freqüentar a escola nos municípios de Minas Gerais, verificando que a porcentagem de escolas com biblioteca, quadras e laboratórios de ciências possui impacto positivo e significativo para a freqüência à escola. Soares (2004b) examinou o impacto da infraestrutura, como condições da sala, limpeza da escola, boas condições de prédios e equipamentos no desempenho dos alunos brasileiros da 8 a série do Ensino Fundamental em Matemática no SAEB 2001, encontrando impacto positivo, mesmo que em magnitudes modestas, das variáveis. Marzocchi e Oliveira (2009) investigaram a associação entre os recursos escolares disponíveis nas escolas públicas brasileiras e o desempenho em Ciências dos alunos participantes do PISA (Programa Internacional de Avaliação dos Alunos) 2006, reportando que as escolas com melhores equipamentos e recursos educacionais podem obter, em média, 6,9 pontos a mais no desempenho. 
Estes resultados demonstram a relevância de investimentos em recursos escolares, mesmo em itens básicos, pois muitas das escolas brasileiras não contam nem sequer com tais itens. Conforme sinalizado por Soares (2004b, p. 17), "ainda não superamos a fase de investimentos básicos nas escolas". Essa é, pois, uma questão que deve compor a agenda política, para a promoção da aprendizagem discente.

\section{Considerações finais}

O mapeamento da situação educacional dos municípios fluminenses, no âmbito do PAR, aponta para uma diversidade de prioridades no que se refere à implementação das políticas públicas nas esferas municipais. Estes dados sinalizam que a melhora da qualidade da educação não está diretamente relacionada à implantação especifica de uma determinada política, mas, antes, está estreitamente relacionada à gestão das políticas educacionais. Nessa direção, Alves (2007a) sinaliza que a adesão de Estados e municípios brasileiros a um programa ou política está, em grande medida, relacionado à postura dos governos federais ou estaduais, no sentido dos mesmos fornecerem estímulos necessários às outras instâncias para a adesão efetiva. O mesmo pode ser dito sobre a efetividade das políticas implementadas nos governos subnacionais, especialmente nos municípios fluminenses. Os achados do presente estudo indicam que não basta implantar as propostas na rede de ensino, é preciso, também, atentar para a materialização de tais propostas no âmbito escolar. Esse é um dos fatores determinantes para a efetividade das políticas educacionais.

Além disso, o estudo aqui desenvolvido indica que não são poucos os desafios que ainda se interpõem para a efetiva melhoria da qualidade da educação brasileira e que as políticas educacionais muito têm a contribuir nesse respeito. Os coeficientes estimados para as políticas públicas implementadas nas esferas fluminenses trazem à tona a importância da discussão sobre a associação entre as políticas públicas educacionais e os indicadores de qualidade, para o incremento da qualidade da educação. Dessa forma, as evidências apontam que a gestão das políticas educacionais é um tema a ser considerado e perseguido de perto pela agenda política.

Outra contribuição importante da pesquisa em questão é a utilização do PAR como uma fonte de diagnóstico da situação educacional das diferentes redes de ensino. Essa contribuição é particularmente importante em decorrência do 
fato de que cada vez mais surgem investigações sobre o tema da avaliação de políticas públicas na área da educação, as quais, por vezes, enfrentam muitos entraves no seu desenvolvimento por não contarem com uma base de informação consolidada acerca de indicadores referentes aos diferentes aspectos educacionais, que permita a comparação entre os entes federados e as redes de ensino. Nesse respeito, o PAR apresenta-se como um "forte aliado." Inegavelmente, representa um instrumento valioso para o diagnóstico da situação educacional de cada instância governamental, apontando as demandas de cada realidade, bem como as prioridades das políticas educacionais aí implementadas. A análise do mesmo aqui possibilitou, em grande medida, estabelecer um panorama da qualidade do Ensino Fundamental nos municípios fluminenses. No entanto, o seu legado para as pesquisas educacionais não para por aí, dado que tal plano constitui-se também um instrumento potencial para a avaliação dos efeitos das atuais políticas educacionais, desenvolvidas no âmbito do PDE. O quadro atual é de renovação e de mudanças no cenário político educacional, o qual precisa ser investigado. Assim, uma vez que o PAR apresenta como finalidade precípua o incremento dos indicadores educacionais até 2011, faz-se necessária uma investigação mais aprofundada do mesmo. Ainda são poucos os estudos sobre ele e todos apontam para a gama de possibilidades de análise que o mesmo apresenta.

Nesse sentido, cabe ressaltar as palavras de Bello (2011, p. 8):

o PAR uma experiência inédita dentro do contexto das políticas públicas implementadas até o momento no país que deve ser analisada para que se torne referência - tanto no que se refere aos aspectos positivos como aos negativos - para o planejamento de novas ações do Estado. Nesse sentido, a elaboração de estudos comparativos entre Estados a fim de que se possam avaliar quais foram as principais demandas identificadas pelos gestores municipais e estaduais no PAR, quais as razões dessas escolhas e, sobretudo, o que isso pode nos revelar sobre a realidade educacional de nosso país, é fundamental.

As investigações sobre o PAR ganham um novo impulso e se fazem ainda mais prementes a partir de 2011, uma vez que o MEC/INEP estabelece que os entes federados poderão fazer um novo diagnóstico da situação educacional local e elaborar o planejamento (PAR) para uma nova etapa (2011 a 2014), com base no IDEB dos últimos anos (2005, 2007 e 2009). 
Surge, então, um cenário rico em dados sobre a educação brasileira e em diversidade de políticas educacionais, configurando um terreno instigante de pesquisa sobre a associação entre tais políticas e a qualidade de ensino. Como dito, o desafio que se coloca para pesquisadores é o de compreender como tais políticas relacionam-se com a evolução dos indicadores educacionais.

\section{Referências}

ALBERNAZ, A; FERREIRA, F; FRANCO, C. Qualidade e equidade no Ensino Fundamental brasileiro. Pesquisa e Planejamento Econômico, Rio de Janeiro, v. 32, n. 3, 2002.

ALVES, F. Qualidade na educação fundamental pública nas capitais brasileiras: tendências, contextos e desafios. 2007. 243 p. Tese (Doutorado em Educação)Pontifícia Universidade Católica do Rio de Janeiro, Rio de Janeiro, 2007a.

. Qualidade da educação fundamental: integrando desempenho e fluxo escolar. Ensaio: Avaliação de Políticas Públicas Educacionais, Rio de Janeiro, v. 15 , n. 57 , p. 525-542, out./dez. 2007 b.

BATISTA, N. Gestão democrática da educação: um estudo de situações e tendências no plano de ações articuladas em municípios do Rio Grande do Sul. In: SIMPÓSIO BRASILEIRO, 25., 2011, São Paulo; CONGRESSO IBEROAMERICANO DE POLÍTICA E ADMINISTRAÇÃO DA EDUCAÇÃO, 2., 2011, São Paulo. Anais... São Paulo: ANPAE, 2011. Disponível em: $<$ http:// www.anpae.org.br/simposio2011/cdrom2011/PDFs/trabalhosCompletos/ comunicacoesRelatos/0425.pdf>. Acesso em: 15 jul. 2011.

BELLO, I. O plano de ações articuladas como estratégia organizacional dos sistemas públicos de ensino: avanços, limites e possibilidades. In: SIMPÓSIO BRASILEIRO, 25., 2011, São Paulo; CONGRESSO IBEROAMERICANO DE POLÍTICA E ADMINISTRAÇÃO DA EDUCAÇÃO, 2., 2011, São Paulo. Anais... São Paulo: ANPAE, 2011. Disponível em: $<$ http:// www.anpae.org.br/simposio2011/cdrom2011/PDFs/trabalhosCompletos/ comunicacoesRelatos/0234.pdf>. Acesso em: 15 jul. 2011. 
BONAMINO, A.; ALVES, F.; FRANCO, C. Qualidade do Ensino Fundamental: políticas, suas possibilidades, seus limites. Educação \& Sociedade, Campinas, v. 28, n.100 (especial), p. 989-1014, out. 2007.

BRASIL. Decreto 6.094 de 24 de abril de 2007. Dispõe sobre a implementação do Plano de Metas Compromisso Todos pela Educação... Brasília, DF, abril de 2007. Disponível em: <http://www.planalto.gov.br/ccivil_03/_Ato2007-2010/2007/ Decreto/D6094.htm> Acesso em: fevereiro de 2009. Diário Oficial da República Federativa do Brasil, Brasília, DF, 25 dezembro 2007.

FARENZENA, N.; MOSNA, R.; SCHUCH, C. Implementação do plano de ações articuladas em municípios do Rio Grande do Sul: uma avaliação. In: SIMPÓSIO BRASILEIRO, 25., 2011, São Paulo; CONGRESSO IBEROAMERICANO DE POLÍTICA E ADMINISTRAÇÃO DA EDUCAÇÃO, 2., 2011, São Paulo. Anais... São Paulo: ANPAE, 2011. Disponível em: <http:// www.anpae.org.br/simposio2011/cdrom2011/PDFs/trabalhosCompletos/ comunicacoesRelatos/0414.pdf $>$. Acesso em: 15 jul. 2011.

FERNANDES, R. Expansão Escolar e Qualidade de Ensino: o Brasil na Década de 1990. 2004. 243 p. Tese (Doutorado em Economia)-Universidade de São Paulo, Faculdade de Economia, Administração e Contabilidade de Ribeirão Preto, FEARP, São Paulo. 2004.

FERNANDES, R.; NATENZON, P. A Evolução Recente do Rendimento Escolar das Crianças Brasileiras: Uma reavaliação dos Dados do SAEB. Estudos em Avaliação Educacional, n. 28, p. 3-22, dez. 2003.

FONTANIVE, N. A capacitação de professores contribui para a aprendizagem dos alunos?: um estudo das relações entre qualificação docente e melhoria de desempenho de estudantes no Ensino Fundamental. 2009. 245 p. Tese (Doutorado em Educação)-Pontifícia Universidade Católica do Rio de Janeiro, Rio de Janeiro, 2009.

FRANCO, C.; BONAMINO, A. A pesquisa sobre característica de escolas eficazes no Brasil: breve revisão dos principais achados e alguns problemas em aberto. Revista do Programa de Pós Graduação: Educação online PUC-Rio, Rio de Janeiro, n. 1, p. 2-13, 2005. Disponível em: <http://www.maxwell.lambda.ele.pucrio.br/ cgibin/db2www/PRG_1356.D2W/input?CdLinPrg=pt>. Acesso em: 15 jul. 2011. 
FRANCO, C.; BONAMINO, A. Eficácia e equidade na educação brasileira: evidências baseadas nos dados do SAEB 2001. Rio de Janeiro: PUC-Rio, 2002. Mimeografado.

FRANCO, C. et al. Qualidade e equidade em educação: reconsiderando o significado de "fatores intra-escolares". Ensaio: Avaliação de Políticas Públicas Educacionais, Rio de Janeiro, v. 15, n. 55, p. 277-298, abr.jun. 2007.

GAZÓLIS, L. Livro didático e aprendizado de leitura no início do Ensino Fundamental. 2007. Dissertação (Mestrado)-Programa de Pós-Graduação em Educação, Pontifícia Universidade Católica do Rio de Janeiro, Rio de Janeiro, 2007.

GORNI, D. Ensino Fundamental de 9 anos: estamos preparados para implantálo? Ensaio: Avaliação de Políticas Públicas Educacionais, Rio de Janeiro, v. 15, n. 54, p. 67-80, jan./mar. 2007.

INEP. INSTITUTO NACIONALDE ESTUDOS E PESQUISAS EDUCACIONAIS ANÍSIO TEIXEIRA. Nota Técnica: Índice de Desenvolvimento da Educação Básica - IDEB. Brasília, DF: MEC, [20--?]. Disponível em: <http://www.inep.gov.br/ download/Ideb/Nota_Tecnica_n1_concepcaoIDEB.pdf $>$. Acesso em: 15 jul. 2013.

. Estatísticas do ideb. Brasília, DF: MEC, 2008a.

. Indicadores demográficos e educacionais. Brasília, DF: MEC, 2008b. Disponível em: <http://portal.mec.gov.br/index.php?option=com content\&task=view\&id=10133>. Acesso em: 15 jul. 2013.

LIBÂNEO, J.; FERREIRA, J.; SEABRA, M. Educação escolar: políticas, estrutura e organização. 6 ed. São Paulo: Cortez, 2008.

MAFASSIOLI, A.; MARCHAND, P. Plano de ações articuladas: competências dos entes federados na sua implementação. In: SIMPÓSIO BRASILEIRO, 25., 2011, São Paulo; CONGRESSO IBERO-AMERICANO DE POLÍTICA E ADMINISTRAÇÃO DA EDUCAÇÃO, 2., 2011, São Paulo. Anais... São Paulo: ANPAE, 2011. Disponível em: $<$ http://www.anpae.org.br/simposio2011/ cdrom2011/PDFs/trabalhosCompletos/comunicacoesRelatos/0057.pdf $>$. Acesso em: 15 jul. 2013. 
MARZOCCHI, M.; OLIVEIRA, A. Interlocução entre autonomia escolar e desempenho: quais as analogias possíveis? In: CONGRESSO BRASILEIRO DE SOCIOLOGIA, 14., 2009. Rio de Janeiro. Anais... Rio de Janeiro: SBS, 2009. Disponível em: <http://starline.dnsalias.com:8080/sbs/ arquivos/16_6_2009_11_59_13.pdf $>$. Acesso em: 15 jul. 2013.

MENEZES-FILHO, N.; AMARAL, L. A Relação entre gastos educacionais e desempenho escolar. São Paulo, 2009 (Mimeografado).

MENEZES-FILHO, N.; RIBEIRO, F. Os determinantes da Melhoria do Rendimento Escolar. In: VELOSO, F.; PESSÔA. S.; HENRIQUES, R.; GIAMBIAGI, F. (Org.). Educação Básica no Brasil: construindo o país do futuro. Rio de Janeiro: Elsevier, 2009.

RIANI, J. Impacto dos fatores familiares, escolares e comunitários na probabilidade de cursar a escola na idade adequada no Ensino Fundamental e Médio. In: ENCONTRO NACIONAL DE ESTUDOS POPULACIONAIS, 14., 2004. Caxambu. Anais... Caxambu: ABEP, 2004. Disponível em: $<$ http://www. abep.nepo.unicamp.br/site_eventos_abep/PDF/ABEP2004_60.pdf $>$. Acesso em: 15 jul. 2013.

SAMMONS, P. As características-chave das escolas eficazes. In: BROOKE, N.; SOARES, J. (Org.). Pesquisa em eficácia escolar: origem e trajetórias. Belo Horizonte: Editora UFMG, 2008.

SAVIANI, D. O plano de desenvolvimento da educação: análise do projeto do MEC. Educação \& Sociedade, Campinas, v. 28, n. 100. especial, p. 1231-1255, out. 2007.

SOARES, J. O efeito da escola no desempenho cognitivo dos seus alunos. REICE: Revista Electrónica IberoAmericana sobre Calidad, Eficácia y Cambio em Educación, v. 2, n. 2, 2004a. Disponível em: http: <//www.ice.deusto.es/ rinace/reice/vol2n2/Soares.pdf > . Acesso em: 15 jul. 2013.

. Qualidade e eqüidade na educação básica brasileira: a evidência do SAEB2001. Archivos Analíticos de Políticas Educativas, Tempe, v. 12, n. 38, $2004 \mathrm{~b}$. Disponível em: <http://epaa.asu.edu?epaa?v12n38/>. Acesso em: 15 jul. 2013. 
SOUSA, B. O plano de ações articuladas (PAR) como instrumento de planejamento da educação: o que há de novo? In: SIMPÓSIO BRASILEIRO, 25., 2011, São Paulo; CONGRESSO IBERO-AMERICANO DE POLÍTICA E ADMINISTRAÇÃO DA EDUCAÇÃO, 2., 2011, São Paulo. Anais... São Paulo: ANPAE, 2011. Disponível em: <http://www.anpae.org.br/simposio2011/ cdrom2011/PDFs/trabalhosCompletos/comunicacoesRelatos/0079.pdf > . Acesso em: 15 jul. 2013.

\section{Educational policies and the quality of education in the municipalities of Rio de Janeiro State: some cutouts}

\section{Abstract}

This article presents the mapping of the educational situation of the municipalities of Rio de Janeiro State, from the analysis of the Articulated Actions plan (PAR), implemented in 2007 by the MEC, highlighting municipal demands in distinct educational areas. In addition, the work covers, by taking a multivariate analysis and adjusting a linear regression model, how differences in average performance in Mathematics for the Fifth Year of Elementary School may be explained by educational policies implemented in the municipalities. The findings of the study point out that the management of educational policies is a theme to be considered and pursued closely by political agenda, as well as the relevance of research to investigate the association between such policies and the evolution of educational indicators.

Keywords: Quality Education. Educational Policies. Articulated Actions Plan (PAR)

\section{Políticas educacionales y la calidad de la educación en los municipios provinciales de Rio de Janeiro: algunos recortes}

\section{Resumen}

Este artículo presenta el mapa de la situación educacional de los municipios provinciales de Río de Janeiro, a partir del análisis del plan de acciones articuladas (PAR) que el MEC - Ministerio de Educación y Salud brasileño - implementó en 2007, destacando las necesidades municipales en diferentes 
áreas educacionales. También, de forma complementaria, el trabajo aborda, ejecutando un análisis multivariado y ajustando un modelo de regresión lineal, como los diferentes promedios en Matemáticas del quinto grado primario pueden explicarse debido a las politicas educacionales implementadas en dichos municipios. Las conclusiones del estudio señalan que la gestión de las políticas educacionales es un tema que la agenda política debe tener en cuenta y destacan también la importancia de realizar más investigaciones sobre la asociación entre dichas políticas y la evolución de los indicadores educacionales.

Palabras clave: Calidad de la Educación. Políticas Educacionales. Plan de Acciones Articuladas (PAR) 